\title{
Prognostic value of pre-transplant mean pulmonary arterial pressure in lung transplant recipients: a single-institution experience
}

\author{
Chi Young Kim¹, Ji Eun Park ${ }^{1}$, Ah Young Leem ${ }^{1}$, Joo Han Song ${ }^{1}$, Song Yee Kim ${ }^{1}$, Kyung Soo Chung ${ }^{1}$, \\ Eun Young Kim ${ }^{1}$, Ji Ye Jung ${ }^{1}$, Young Ae Kang ${ }^{1}$, Young Sam Kim ${ }^{1}$, Joon Chang ${ }^{1}$, Jin Gu Lee ${ }^{2}$, Hyo Chae \\ Paik $^{2}$, Moo Suk Park ${ }^{1}$ \\ ${ }^{1}$ Division of Pulmonology, Department of Internal Medicine, Institute of Chest Diseases, Severance Hospital, Yonsei University College of Medicine, \\ Seoul, Republic of Korea; ${ }^{2}$ Department of Thoracic \& Cardiovascular Surgery, Severance Hospital, Yonsei University College of Medicine, Seoul, \\ Republic of Korea \\ Contributions: (I) Conception and design: CY Kim, MS Park; (II) Administrative support: CY Kim, JY Park, SY Kim, MS Park; (III) Provision of \\ study materials or patients: CY Kim, JY Park, SY Kim, MS Park; (IV) Collection and assembly of data: CY Kim, JY Park, SY Kim, MS Park; (V) \\ Data analysis and interpretation: All authors; (VI) Manuscript writing: All authors; (VII) Final approval of manuscript: All authors. \\ Correspondence to: Moo Suk Park, MD, PhD. Division of Pulmonology, Department of Internal Medicine, Severance Hospital, Institute of Chest \\ Diseases, Yonsei University College of Medicine, 50-1, Yonsei-ro, Seodaemun-gu, Seoul 120-752, Republic of Korea. Email: pms70@yuhs.ac.
}

Background: Currently, lung transplantation (LTX) is considered to be a curative treatment option in patients with end-stage lung disease. Although pulmonary hypertension (PH), confirmed by cardiac catheterization, is a prognostic factor in patients undergoing LTX, the prognostic value of PH in Asian lung transplant recipients remains uncertain. In this study, we aimed to determine whether PH before LTX may serve as a prognostic factor for survival in Asian patients.

Methods: The medical records of 50 patients [male, 27; female, 23; mean age, 51.0 (41.0-60.0) years], who received preoperative right heart catheterization (RHC) and echocardiography before single or double LTX at Severance Hospital between January 2010 and December 2014, were reviewed. The relationship between 1-year survival after LTX and PH [mean pulmonary arterial pressure (mPAP) $\geq 25 \mathrm{mmHg}$ at rest] was evaluated.

Results: The mean right ventricular systolic pressure and mPAP were 48.5 (22.8) and 30.0 (24.0-40.0) $\mathrm{mmHg}$. Of the 50 patients, $17(34.0 \%)$ died within a year after LTX. The 1-year survival rate among patients with $\mathrm{mPAP} \geq 25 \mathrm{mmHg}(58.8 \%)$ was lower than the survival rate among patients with $\mathrm{mPAP}<25 \mathrm{mmHg}(87.5 \%)$. Pre-transplantation mPAP of $\geq 25 \mathrm{mmHg}$ was associated with post-transplantation survival [hazard ratio (HR), 4.832; 95\% confidence interval (CI), 1.080-21.608, $\mathrm{P}=0.039]$. The presence of preoperative $\mathrm{PH}$ was also associated with an increased risk of postoperative complications.

Conclusions: Confirmation of $\mathrm{PH}$ via preoperative cardiac catheterization was associated with the prognosis of the patient after LTX. Clinicians should consider the necessity for early transplantation surgery before the $\mathrm{mPAP}$ reaches $\geq 25 \mathrm{mmHg}$.

Keywords: Lung transplantation (LTX); prognosis; hypertension; pulmonary

Submitted Sep 13, 2017. Accepted for publication Feb 12, 2018.

doi: $10.21037 /$ jtd.2018.03.46

View this article at: http://dx.doi.org/10.21037/jtd.2018.03.46 


\section{Introduction}

Management approaches for various intractable lung diseases have been transformed with the advancement of lung transplantation (LTX), which is one of the treatment options utilized at the endpoint of several lung diseases. Transplantation of other solid organs has produced better results and undergone greater improvement than LTX; thus, the outcomes of LTX remain among the worst overall for organ transplantation $(1,2)$. However, the frequency and success rate of LTX have improved in recent years, with the increased success attributable to advances in post-LTX immunosuppression treatment $(2,3)$; nevertheless, progress in LTX outcomes remains a challenging area of medicine. The survival rate associated with LTX has been increasing, such that the majority of deaths after LTX occur within the first year (4). Therefore, the identification of prognostic factors of 1-year mortality in lung transplant recipients might facilitate improvement of long term clinical outcomes after LTX.

There is a growing body of evidence that pulmonary hypertension $(\mathrm{PH})$ associated with lung disease is a predictor of disease severity and mortality in patients awaiting LTX (5-7). Patients with PH suffer hypoxia, hypercapnia and respiratory acidosis, as a result of increased peripheral vascular resistance and right heart failure $(8,9)$; these conditions can eventually lead to death. Previous studies have reported that $\mathrm{PH}$, when confirmed by cardiac catheterization, is an independent predictive factor for survival after LTX (7,10-13). In addition, several studies have also analyzed post-LTX prognosis via echocardiography (14-16). However, almost all studies were exclusively designed for idiopathic pulmonary fibrosis (IPF) or other individual lung diseases. Moreover, there is a lack of consensus regarding predictive factors between IPF patients and patients who have other lung pathologies (17).

Despite the increasing popularity of LTX, there continue to be limited reports on the prognostic value of $\mathrm{PH}$ in lung transplant recipients. In addition, because of the small number of recipients of LTX in Asia, there are no reports in an Asian population regarding the clinical significance of $\mathrm{PH}$ in post-LTX survival. To determine the impact of $\mathrm{PH}$ on post-LTX survival, this study analyzed the characteristics and prognoses of lung transplant recipients with or without preoperative $\mathrm{PH}$ via echocardiography and right heart catheterization (RHC) in a Korean population.

\section{Methods}

\section{Study design and population}

We reviewed the medical records of 83 patients who underwent single or double LTX between January 2010 and July 2014 at Severance Hospital, Yonsei University, Republic of Korea. We excluded patients who did not undergo preoperative echocardiography or cardiac catheterization within 1 year prior to LTX, as well as those who missed follow-up echocardiography within 3 months after LTX. Thus, of the 83 patients whose records were initially reviewed, 50 were included in the study. From the database, we extracted all variables related to patient demographic characteristics and pre- and postoperative outcomes, in order to evaluate the relationship between $\mathrm{PH}$ and 1-year survival after LTX. Patient survival status was determined on the basis of hospital records. Donor data were collected from the Korean Network of Organ Sharing (KONOS) database. Additional variables included demographic characteristics, ischemic time, and donorrecipient size mismatch. All donated lungs from declared brain-dead patients were preserved in low-potassium dextran solution (Perfadex; Duraent Biologicals, Hyderabad, India). We divided the study subjects into two groups, according to their $\mathrm{PH}$ status.

\section{RHC and echocardiography}

RHC was performed at rest using a Swan-Ganz catheter. $\mathrm{PH}$ was defined as an increase in resting mean pulmonary arterial pressure (mPAP) of $\geq 25 \mathrm{mmHg}$, as assessed by RHC, using European Society of Cardiology and European Respiratory Society guidelines (18). Other echocardiographic variables were collected, such as ejection fraction (EF); right arterial pressure (RAP); regional wall motion abnormality (RWMA); ratio of mitral peak velocity of early filling (E) to early diastolic mitral annular velocity (E'), i.e., E/E'; and RV systolic pressure (RVSP). The characteristics of echocardiography were compared with RHC data, and correlation analysis was performed to investigate correlations with $\mathrm{PH}$.

\section{Statistical analysis}

All data were analyzed using SPSS version 23 (IBM, Armonk, NY, USA). Data are expressed as mean values with standard deviations or median values with interquartile ranges (IQRs), as appropriate. Continuous 
variables were compared by Student's $t$-test; categorical variables were compared by either the Chi-squared test or Fisher's exact test, as appropriate. Comparison of survival between patients with and without preoperative $\mathrm{PH}$ was performed by the log-rank test. The relationship between RHC and echocardiography-derived hemodynamics was assessed using the Pearson correlation. One-year survival following LTX was analyzed by Kaplan-Meier analysis; this measurement was compared between recipients with and without preoperative $\mathrm{PH}$. Association of echocardiographic and hemodynamic parameters with clinical outcomes was evaluated by Cox proportional hazards regression analysis. Hazard ratios (HRs) and 95\% confidence intervals (CIs) were calculated. In all statistical analyses, a two-tailed $\mathrm{P}$ value of $<0.05$ was considered to be statistically significant.

\section{Ethical approval}

The study protocol was approved by the institutional review board of Severance Hospital (approval No. 2013-0522-019). In addition, this study was conducted in compliance with the principles set in the 2000 Declaration of Helsinki, as well as the 2008 Declaration of Istanbul.

\section{Results}

\section{Baseline characteristics of lung transplant recipients}

Table 1 describes the baseline characteristics of all patients who were included in this analysis, comprising 50 [27 males $(54 \%)$ and 23 females (46\%)] patients. The mean age of the patients was 51.0 (41.0-60.0) years; 47 (94.0\%) patients underwent double LTX. On the basis of mPAP values, 34 patients $(68.0 \%)$ were classified into the $\mathrm{PH}$ group; the remaining patients comprised the non-PH group. Comparison of demographic, hemodynamic, and pulmonary function characteristics among lung transplant recipients was performed, according to $\mathrm{PH}$ status. The distribution of underlying lung diseases was as follows: IPF, 22 patients (44.0\%); lymphangioleiomyomatosis, 8 patients (16.0\%); connective tissue disease, 6 patients $(12.0 \%)$; bronchiectasis, 5 patients (10.0\%); bronchiolitis obliterans after stem cell transplantation, 4 patients (8.0\%); diffuse panbronchiolitis, 2 patients (4.0\%); and others [chronic obstructive pulmonary disease, other pulmonary fibrosis, and pulmonary Langerhans cell histiocytosis, 1 patient each $(2.0 \%)]$. There was no statistically significant difference in the distribution of the underlying diseases. Pulmonary function tests were administered before LTX; lung transplant recipients exhibited underlying lung diseases with severe restrictive patterns, as evidenced by the relatively low mean values of functional vital capacity $(45.6 \% \pm 16.3 \%)$ and diffusing capacity of the lung for carbon monoxide $\left(\mathrm{DL}_{\mathrm{CO}}\right.$; $37.8 \% \pm 18.8 \%)$. The mean values of preoperative RVSP and mPAP (determined by echocardiography and RHC, respectively) were $48.5 \pm 22.8$ and $30.0(24.0-40.0) \mathrm{mmHg}$, respectively. Comparison of baseline characteristics revealed that there were significant differences between the two groups regarding most hemodynamic variables, suggesting that hemodynamic variables may act as a prognostic factor; however, the only significant prognostic factors in both univariate analysis and multivariate analysis were mPAP and RAP.

\section{Clinical predictors of 1-year survival after LTX}

Of the 50 patients in the study, 17 (34.0\%) died within 1 year after LTX. The 1-year survival rate of lung transplant recipients was higher in the $\mathrm{PH}$ group; the survival rates of patients with and without $\mathrm{PH}$ were $58.8 \%$ and $87.0 \%$, respectively (log-rank test, $\mathrm{P}=0.030$; Figure 1$)$. Table 2 presents the results of univariate analysis of predictive values for 1-year survival after LTX. Old age, male sex, higher $\mathrm{BMI}, \mathrm{RAP}$, and mPAP were identified as independent prognostic factors.

The results of multivariate Cox proportional hazards analysis of age, sex, BMI, underlying disease (IPF vs. nonIPF), and $\mathrm{mPAP}$ - all of which were identified as significant prognostic factors in univariate analysis-revealed an $\mathrm{HR}$ of 4.832 (95\% CI, 1.080-21.608; $\mathrm{P}=0.039$ ) for survival in patients with $\mathrm{mPAP} \geq 25 \mathrm{mmHg}$. These results strongly suggest that preoperative $\mathrm{PH}$ significantly affects the chances of 1-year survival (Table 3).

\section{Postoperative complications among lung transplant recipients}

Table 4 presents the comparison of postoperative complications, occurring within 3 months of LTX, in lung transplant recipients. Complications such as sepsis, acute kidney injury, acute rejection, postoperative bleeding, and grade 3 primary graft dysfunction were more frequent in the $\mathrm{PH}$ group than in the non-PH group. The proportion of complications was higher in the $\mathrm{PH}$ group than in the non-PH group. 
Table 1 Comparison of baseline characteristics of patients with and without pulmonary hypertension before lung transplantation ( $\mathrm{N}=50$ )

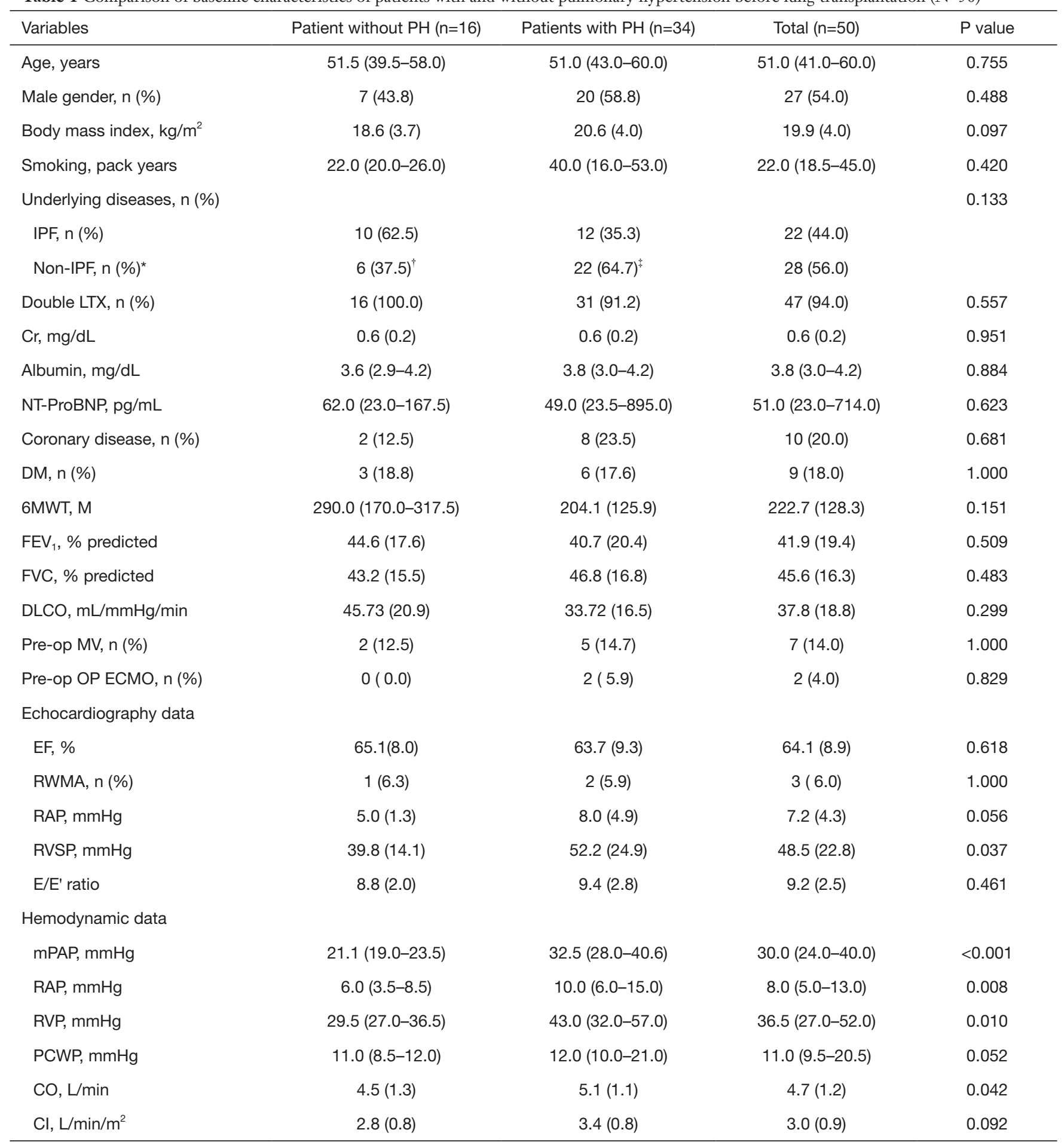

Table 1 (continued) 
Table 1 (continued)

\begin{tabular}{|c|c|c|c|c|}
\hline Variables & Patient without $\mathrm{PH}(\mathrm{n}=16)$ & Patients with $\mathrm{PH}(\mathrm{n}=34)$ & Total $(n=50)$ & $P$ value \\
\hline \multicolumn{5}{|l|}{ Donor } \\
\hline Age, years & $44.0(34.5-51.0)$ & $41.0(37.0-47.0)$ & $42.0(37.0-50.0)$ & 0.487 \\
\hline Male gender, n (\%) & $8(50.0)$ & $25(73.5)$ & $33(66.0)$ & 0.139 \\
\hline Body mass index, $\mathrm{kg} / \mathrm{m}^{2}$ & $22.4(2.9)$ & $22.4(3.0)$ & $22.4(2.9)$ & 0.982 \\
\hline Ischemic time, $\min$ & $219.5(160.0-265.5)$ & $215.0(181.5-251.0)$ & $216.0(176.0-254.5)$ & 0.875 \\
\hline Size mismatch, n (\%) & $4(25.0)$ & $7(20.6)$ & $11(22.0)$ & 1.000 \\
\hline
\end{tabular}

Values are expressed as mean (SD) or median (IQR). *, the distribution of underlying lung diseases; ${ }^{\dagger}$, bronchiolitis obliterans after stem cell transplantation, 4 (25.0\%); lymphangioleiomyomatosis, 1 (6.3\%); connective tissue disease, 1 (6.3\%); ${ }^{\ddagger}$, lymphangioleiomyomatosis, 7 (20.6\%); bronchiectasis, 5 (14.7\%); connective tissue disease, 5 (14.7\%); diffuse panbronchiolitis, 2 (5.9\%); chronic obstructive pulmonary disease, 1 (2.9\%); pulmonary Langerhans cell histiocytosis, 1 (2.9\%); other pulmonary fibrosis, 1 (2.9\%). IPF, idiopathic pulmonary fibrosis; $\mathrm{Cr}$, serum creatinine; NT-proBNP, n-terminal pro-brain natriuretic peptide; Coronary disease, need a medical treatment in preoperative coronary angiography; DM, diabetes mellitus; $6 \mathrm{MWT}, 6$ minute walk test; $\mathrm{FEV}_{1}$, forced expiratory volume in $1 \mathrm{~s}$; FVC, forced vital capacity; DLCO, diffusion capacity for carbon monoxide; pre-op, preoperative; MV, mechanical ventilation; ECMO, extracorporeal membrane oxygenation; EF, ejection fraction; RWMA, regional wall motion abnormality; RAP, right arterial pressure; RVSP, right ventricular systolic pressure; $E / E^{\prime}$, ratio of mitral peak velocity of early filling $(E)$ to early diastolic mitral annular velocity (E'); mPAP, mean pulmonary arterial pressure; RVP, right ventricular pressure; PCWP, pulmonary capillary wedge pressure; CO, cardiac output; $\mathrm{Cl}$, cardiac index; SD, standard deviation; IQR, interquartile range.

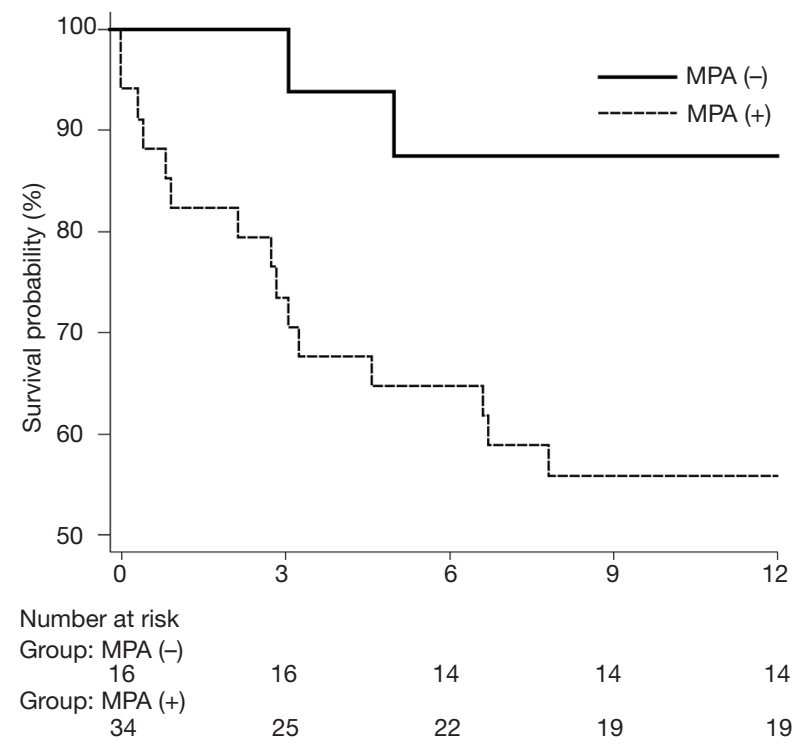

Figure 1 Kaplan-Meier survival curve for 1-year mortality after lung transplantation, according to pulmonary hypertension status. PAP, pulmonary arterial pressure.

\section{Discussion}

This study investigated the association between 1-year mortality and preoperative $\mathrm{PH}$ among patients who underwent LTX, revealing higher rates of 1-year mortality and postoperative complications among patients with preoperative $\mathrm{PH}$, relative to patients without preoperative $\mathrm{PH}$. Thus, the presence of preoperative $\mathrm{PH}$ was associated with an increased risk of postoperative complications and mortality.

The presence of $\mathrm{PH}$ is a significant prognostic factor in patients with end-stage lung diseases. Among patients with COPD, up to $90 \%$ of those with stage IV disease (according to the Global Initiative for Chronic Obstructive Lung Disease guidelines) demonstrate $\mathrm{mPAP}$ of $>20 \mathrm{mmHg}$ (8). In addition, the prevalence of $\mathrm{PH}$ among patients with IPF ranges from $31.6 \%$ to $84 \%(10,13,19)$. Similarly, in various lung diseases, most patients develop PH with disease progression (17). It is interesting to note that, among lung transplant recipients in the present study, preoperative $\mathrm{PH}$ was associated with poor 
Table 2 Results of univariate analysis of prognostic indicators for 1-year mortality after lung transplantation

\begin{tabular}{|c|c|c|}
\hline Variables & $\mathrm{HR}(95 \% \mathrm{Cl})$ & $P$ value \\
\hline Age, years & $1.085(1.030-1.143)$ & 0.002 \\
\hline Male gender, n (\%) & $0.416(0.146-1.181)$ & 0.099 \\
\hline Body mass index, $\mathrm{kg} / \mathrm{m}^{2}$ & $1.249(1.113-1.401)$ & $<0.001$ \\
\hline Smoking, pack years & $1.018(0.985-1.052)$ & 0.292 \\
\hline Underlying disease & & 0.123 \\
\hline IPF & Reference range & \\
\hline Non-IPF* & $0.467(0.177-1.229)$ & \\
\hline Double LTX & $2.913(0.663-12.794)$ & 0.157 \\
\hline Coronary disease & $0.481(0.159-1.368)$ & 0.170 \\
\hline DM & $1.444(0.470-4.439)$ & 0.521 \\
\hline 6MWT, M & $0.999(0.995-1.004)$ & 0.766 \\
\hline \multicolumn{3}{|l|}{ Echocardiography data } \\
\hline $\mathrm{EF}, \%$ & $1.019(0.963-1.079)$ & 0.514 \\
\hline RWMA, N (\%) & $0.801(0.106-6.047)$ & 0.851 \\
\hline $\mathrm{RAP}, \mathrm{mmHg}$ & $1.044(0.943-1.156)$ & 0.409 \\
\hline RVSP, $\mathrm{mmHg}$ & $1.005(0.984-1.027)$ & 0.615 \\
\hline E/E' ratio & $1.116(0.944-1.320)$ & 0.200 \\
\hline \multicolumn{3}{|l|}{ Hemodynamic data } \\
\hline $\mathrm{mPAP} \geq 25, \mathrm{mmHg}$ & $4.444(1.015-19.454)$ & 0.048 \\
\hline $\mathrm{RAP}, \mathrm{mmHg}$ & $1.086(1.021-1.155)$ & 0.008 \\
\hline $\mathrm{RVP}, \mathrm{mmHg}$ & $1.008(0.989-1.027)$ & 0.407 \\
\hline PCWP, mmHg & $1.035(0.985-1.088)$ & 0.177 \\
\hline $\mathrm{CO}, \mathrm{L} / \mathrm{min}$ & $1.278(0.717-2.277)$ & 0.405 \\
\hline $\mathrm{Cl}, \mathrm{L} / \mathrm{min} / \mathrm{m}^{2}$ & $0.659(0.240-1.808)$ & 0.659 \\
\hline Pre-op MV & $2.491(0.88-7.686)$ & 0.112 \\
\hline Pre-op ECMO & $1.923(0.254-14.557)$ & 0.527 \\
\hline \multicolumn{3}{|l|}{ Donor } \\
\hline Age, years & $0.983(0.944-1.025)$ & 0.425 \\
\hline Male gender & $0.612(0.197-1.898)$ & 0.395 \\
\hline Body mass index, $\mathrm{kg} / \mathrm{m}^{2}$ & $0.948(0.794-1.131)$ & 0.551 \\
\hline
\end{tabular}

Table 2 (continued)
Table 2 (continued)

\begin{tabular}{lcc}
\hline Variables & HR $(95 \% \mathrm{Cl})$ & $\mathrm{P}$ value \\
\hline Smoking, pack years & $0.933(0.825-1.054)$ & 0.265 \\
Ischemic time, min & $1.004(0.997-1.012)$ & 0.216 \\
Size mismatch & $1.972(0.727-5.347)$ & 0.182 \\
\hline
\end{tabular}

*, the distribution of underlying lung diseases: lymphangioleiomyomatosis, 8 (28.6\%); connective tissue disease, 6 (21.4\%); bronchiectasis, 5 (17.6); bronchiolitis obliterans after stem cell transplantation, 4 (14.3\%); diffuse panbronchiolitis, 2 (7.1); chronic obstructive pulmonary disease, 1 (3.6\%); pulmonary Langerhans cell histiocytosis, 1 (3.6\%); other pulmonary fibrosis, 1 (3.6\%). HR, hazard ratio; $\mathrm{Cl}$, confidence interval; mPAP, mean pulmonary arterial pressure; IPF, idiopathic pulmonary fibrosis; Coronary disease, need a medical treatment in preoperative coronary angiography; DM, diabetes mellitus; 6MWT, 6 minute walk test; EF, ejection fraction; RWMA, regional wall motion abnormality; RAP, right arterial pressure; RVSP, right ventricular systolic pressure; E/E', ratio of mitral peak velocity of early filling $(E)$ to early diastolic mitral annular velocity (E'); RVP, right ventricular pressure; PCWP, pulmonary capillary wedge pressure; $\mathrm{CO}$, cardiac output; pre-op, preoperative; MV, mechanical ventilation; ECMO, extracorporeal membrane oxygenation; PGD, primary graft dysfunction.

Table 3 Results of multivariate analysis of prognostic indicators for 1-year mortality after lung transplantation

\begin{tabular}{lcc}
\hline Variables & $\mathrm{HR}(95 \% \mathrm{Cl})$ & $\mathrm{P}$ value \\
\hline Age, years & $1.067(1.006-1.132)$ & 0.030 \\
Male gender & $1.007(0.244-4.157)$ & 0.992 \\
BMl, kg/m & $1.146(1.003-1.309)$ & 0.045 \\
IPF vs. non-IPF & $0.822(0.190-3.566)$ & 0.794 \\
RAP, mmHg & $1.028(0.949-1.114)$ & 0.492 \\
mPAP $\geq 25, \mathrm{mmHg}$ & $4.832(1.080-21.608)$ & 0.039 \\
\hline
\end{tabular}

HR, hazard ratio; Cl, confidence interval; BMI, body mass index; IPF, idiopathic pulmonary fibrosis; RAP, right arterial pressure; mPAP, mean pulmonary arterial pressure. 
Table 4 Postoperative complications within 3 months in lung transplant recipients

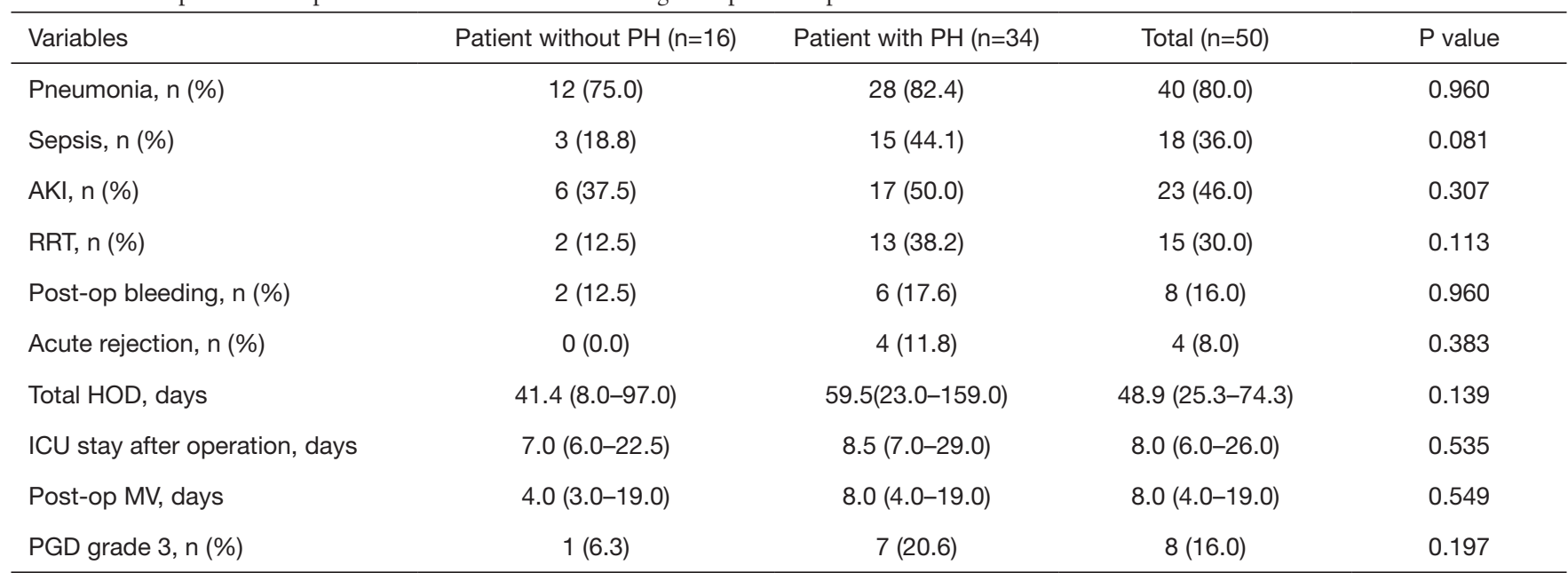

Values are expressed as mean (SD) or median (IQR). SD, standard deviation; IQR, interquartile range; PH, pulmonary hypertension; AKI, acute kidney injury; RRT, renal replacement therapy; post-op, post-operative; HOD, day of hospital stay; ICU, intensive care unit; MV, mechanical ventilation; PGD, primary graft dysfunction.

prognosis for 1-year survival post-LTX.

Several studies and guidelines have defined $\mathrm{PH}$ as mPAP $\geq 25 \mathrm{mmHg}$ in patients with or without underlying diseases; in addition, RHC has been utilized as the "gold standard" for $\mathrm{PH}$ diagnosis $(9,17,20)$. In the past, chest $\mathrm{X}$-ray imaging and echocardiography were used to determine the presence and severity of $\mathrm{PH}$ (17). However, given its relatively high accuracy in the evaluation of $\mathrm{PH}$ status among lung transplant recipients, RHC is increasingly used in preand postoperative evaluation of $\mathrm{PH}$. Although $\mathrm{RHC}$ is the most accurate method to diagnose $\mathrm{PH}$, it is an invasive procedure. Therefore, echocardiography is preferred as the initial screening modality for diagnosis of PH. A few studies have used echocardiography to investigate mortality among lung transplant recipients with poor RV function $(15,16,21)$.

However, this diagnostic technology requires estimates of tricuspid regurgitation jet velocity and is associated with underestimation of pressures in patients with high PAP, as well as overestimation of PAP in patients without significant elevation $(22,23)$. In the present study, the presence of $\mathrm{PH}$ was found in $68 \%$ of patients by RHC, whereas it was found in $77 \%$ of patients by use of echocardiography [defined as a pulmonary artery systolic pressure (PASP) of $>35 \mathrm{mmHg}$. Unfortunately, there was no correlation between echocardiography and survival (HR 1.005; $95 \%$ CI, 0.984-1.027; $\mathrm{P}=0.615$ ). There was a positive correlation was observed between PASP estimated by echocardiography and measured by RHC $(r=0.584, \mathrm{P}<0.001)$. Although there is a good correlation in baseline PASP between echocardiography and RHC, echocardiographic $\mathrm{PH}$ measurements alone are not sufficient to monitor changes in PASP or progression of $\mathrm{PH}$, as described in previous studies (24). Although it may serve as a good screening tool, echocardiographic $\mathrm{PH}$ measurement alone is not sufficient to predict mortality or postoperative outcome. Further large prospective cohort studies are required regarding the diagnosis of $\mathrm{PH}$ by echocardiography.

In contrast to the present findings, Whitson et al. reported a lack of strong evidence for a relationship between preoperative $\mathrm{PH}$ and postoperative mortality (17). Furthermore, several studies have been unable to identify a statistically significant difference in survival between patients with $\mathrm{PH}$ and patients without $\mathrm{PH}(25,26)$. Because of these inconsistent results, the impact of preoperative $\mathrm{PH}$ on postoperative mortality is still controversial. However, most previous studies, including a large prospective cohort study, have reported high mortality or poor outcomes among lung transplant recipients with $\mathrm{PH}$-associated lung disease $(7,10-13,17,19,27-30)$. In addition, the variation in the impact of $\mathrm{PH}$ on post-transplantation mortality might be attributable to the heterogeneity of end-stage lung diseases among the present study population. In a recent publication, Gries et al. also reported differences in patient survival related to the underlying lung disease (30).

A growing body of evidence suggests that age at operation, sex, BMI, preoperative albumin level, kidney 
function, ischemic time, and size mismatch are significant prognostic factors for survival after LTX (7,21,30-32). The present findings differ from those of some previous reports regarding survival after LTX. In this study, significant prognostic factors for post-LTX survival were limited to age, sex, BMI, and $\mathrm{PH}$ (mPAP $\geq 25 \mathrm{mmHg}$ ). Upon multivariate analysis-performed to exclude the effect of non-PH factors, including underlying disease (IPF or nonIPF), on survival - we found that the severity of $\mathrm{PH}$, as defined by mPAP, was a prognostic factor for 1-year survival in lung transplant recipients.

Unfortunately, most studies that have evaluated the risk factors of post-LTX mortality were performed in North America and Europe. As the medical environment and causes of LTX in Korea are very different relative to the previous studies, these differences may also affect the prognoses of patients undergoing LTX. Furthermore, the mortality rate in patients awaiting LTX in Korea was higher than in other countries (33-35). This may be attributable to the lack of donated lungs and the low utilization rate of donated lungs from brain-dead patients, which are the major obstacles to LTX in Korea, relative to other countries (36).

To our knowledge, this was the first study to evaluate the clinical significance of post-LTX PH in Asian patients. Our results clearly demonstrated a significant correlation between mPAP and 1-year survival after LTX. In addition, the rate and severity of postoperative complications, such as sepsis, multi-organ dysfunction, postoperative bleeding, postoperative gastrointestinal bleeding, and grade 3 primary graft dysfunction, were higher among patients with $\mathrm{PH}$ than among patients without $\mathrm{PH}$. For these reasons, we believe that $\mathrm{PH}$ is a significant prognostic factor for postLTX survival.

In chronic lung diseases associated with $\mathrm{PH}, \mathrm{RV}$ function is strongly influenced by the afterload (i.e., the underlying lung disease status) (17). Additionally, $\mathrm{PH}$ also causes distortion of cardiac geometry; however, postLTX echocardiographic findings have demonstrated reverse remodeling of the distorted cardiac geometry (37). Thus, for a variety of reasons, severe pulmonary disease affects both the right and left ventricles and leads to $\mathrm{PH}$ (38), which is considered to be associated with increased mortality. There is an increasing effort to produce evidence supporting this claim in specific lung diseases, such as cystic fibrosis $(26,39,40)$. Collectively, these findings suggest that the presence of PH before LTX might affect the prognosis in lung transplant recipients. Therefore, further studies, involving a large number of patients with various endstage lung diseases, are required to evaluate the prognostic implication of preoperative $\mathrm{PH}$ in the clinical outcome of LTX.

Limitations of the present study include its relatively small sample size and retrospective study design solely involving medical record review. In addition, there is no apparent difference in the prognosis between severe $\mathrm{PH}$ and mild to moderate $\mathrm{PH}$; this requires additional investigation. Despite these limitations, the strength of this study is that this was the first study to evaluate the prognostic significance of preoperative $\mathrm{PH}$ in Asian patients; moreover, the data were derived from a single center cohort. Considering that differences in ethnicity influence the outcome in patients with end-stage lung disease, data from our study could provide useful information regarding the prognosis of Asian patients undergoing LTX.

In conclusion, patients with $\mathrm{PH}$ exhibited higher 1-year mortality after LTX, relative to patients without $\mathrm{PH}$. $\mathrm{PH}$ associated with lung disease has been shown to be a predictor of the severity of disease and mortality in patients awaiting LTX. Thus, the evaluation of $\mathrm{PH}$ by preoperative RHC might be essential in patients who are awaiting LTX. Larger prospective studies are required to verify the benefit of early transplantation in patients with $\mathrm{PH}$, following evaluation by echocardiography and RHC. Furthermore, earlier transplantation should be considered before the occurrence of end-stage lung disease in patients with $\mathrm{PH}$.

\section{Acknowledgements}

None.

\section{Footnote}

Conflicts of Interest: The authors have no conflicts of interest to declare.

Ethical Statement: The study protocol was approved by the institutional review board of Severance Hospital (approval No. 2013-0522-019). In addition, this study was conducted in compliance with the principles set in the 2000 Declaration of Helsinki, as well as the 2008 Declaration of Istanbul.

\section{References}

1. Christie JD, Edwards LB, Kucheryavaya AY, et al. The 
Registry of the International Society for Heart and Lung Transplantation: Twenty-eighth Adult Lung and HeartLung Transplant Report--2011. J Heart Lung Transplant 2011;30:1104-22.

2. Studer SM, Levy RD, McNeil K, et al. Lung transplant outcomes: a review of survival, graft function, physiology, health-related quality of life and cost-effectiveness. Eur Respir J 2004;24:674-85.

3. Strueber M, Warnecke G, Fuge J, et al. Everolimus Versus Mycophenolate Mofetil De Novo After Lung Transplantation: A Prospective, Randomized, Open-Label Trial. Am J Transplant 2016;16:3171-80.

4. Sabashnikov A, Weymann A, Mohite PN, et al. Risk factors predictive of one-year mortality after lung transplantation. Eur J Cardiothorac Surg 2014;46:e82-8.

5. Hayes D Jr, Black SM, Tobias JD, et al. Prevalence of Pulmonary Hypertension and its Influence on Survival in Patients With Advanced Chronic Obstructive Pulmonary Disease Prior to Lung Transplantation. Copd 2016;13:50-6.

6. Hayes D Jr, Black SM, Tobias JD, et al. Influence of pulmonary hypertension on survival in advanced lung disease. Lung 2015;193:213-21.

7. Hayes D Jr, Black SM, Tobias JD, et al. Influence of Pulmonary Hypertension on Patients With Idiopathic Pulmonary Fibrosis Awaiting Lung Transplantation. Ann Thorac Surg 2016;101:246-52.

8. Wrobel JP, Thompson BR, Williams TJ. Mechanisms of pulmonary hypertension in chronic obstructive pulmonary disease: a pathophysiologic review. J Heart Lung Transplant 2012;31:557-64.

9. Seeger W, Adir Y, Barbera JA, et al. Pulmonary hypertension in chronic lung diseases. J Am Coll Cardiol 2013;62:D109-16.

10. Shorr AF, Wainright JL, Cors CS, et al. Pulmonary hypertension in patients with pulmonary fibrosis awaiting lung transplant. Eur Respir J 2007;30:715-21.

11. Hayes D Jr, Tumin D, Budev MM, et al. Adverse outcomes associated with pulmonary hypertension in chronic obstructive pulmonary disease after bilateral lung transplantation. Respir Med 2017;128:102-8.

12. Andersen KH, Schultz HH, Nyholm B, et al. Pulmonary hypertension as a risk factor of mortality after lung transplantation. Clin Transplant 2016;30:357-64.

13. Nadrous HF, Pellikka PA, Krowka MJ, et al. Pulmonary hypertension in patients with idiopathic pulmonary fibrosis. Chest 2005;128:2393-9.

14. Rudski LG, Lai WW, Afilalo J, et al. Guidelines for the echocardiographic assessment of the right heart in adults: a report from the American Society of Echocardiography endorsed by the European Association of Echocardiography, a registered branch of the European Society of Cardiology, and the Canadian Society of Echocardiography. J Am Soc Echocardiogr 2010;23:685713; quiz 86-8.

15. Kusunose K, Tsutsui RS, Bhatt K, et al. Prognostic value of RV function before and after lung transplantation. JACC Cardiovasc Imaging 2014;7:1084-94.

16. Porteous MK, Ky B, Kirkpatrick JN, et al. Diastolic Dysfunction Increases the Risk of Primary Graft Dysfunction after Lung Transplant. Am J Respir Crit Care Med 2016;193:1392-400.

17. Hayes D Jr, Higgins RS, Black SM, et al. Effect of pulmonary hypertension on survival in patients with idiopathic pulmonary fibrosis after lung transplantation: an analysis of the United Network of Organ Sharing registry. J Heart Lung Transplant 2015;34:430-7.

18. Galie N, Humbert M, Vachiery JL, et al. 2015 ESC/ERS Guidelines for the diagnosis and treatment of pulmonary hypertension: The Joint Task Force for the Diagnosis and Treatment of Pulmonary Hypertension of the European Society of Cardiology (ESC) and the European Respiratory Society (ERS): Endorsed by: Association for European Paediatric and Congenital Cardiology (AEPC), International Society for Heart and Lung Transplantation (ISHLT). Eur Respir J 2015;46:903-75.

19. Lettieri CJ, Nathan SD, Barnett SD, et al. Prevalence and outcomes of pulmonary arterial hypertension in advanced idiopathic pulmonary fibrosis. Chest 2006;129:746-52.

20. Rosenkranz S, Preston IR. Right heart catheterisation: best practice and pitfalls in pulmonary hypertension. Eur Respir Rev 2015;24:642-52.

21. Armstrong HF, Schulze PC, Kato TS, et al. Right ventricular stroke work index as a negative predictor of mortality and initial hospital stay after lung transplantation. J Heart Lung Transplant 2013;32:603-8.

22. Brecker SJ, Gibbs JS, Fox KM, et al. Comparison of Doppler derived haemodynamic variables and simultaneous high fidelity pressure measurements in severe pulmonary hypertension. Br Heart J 1994;72:384-9.

23. Arcasoy SM, Christie JD, Ferrari VA, et al.

Echocardiographic assessment of pulmonary hypertension in patients with advanced lung disease. Am J Respir Crit Care Med 2003;167:735-40.

24. Opitz C, Rosenkranz S, Ghofrani HA, et al. ESC guidelines 2015 pulmonary hypertension: diagnosis and 
treatment. Dtsch Med Wochenschr 2016;141:1764-9.

25. Andersen KH, Iversen M, Kjaergaard J, et al. Prevalence, predictors, and survival in pulmonary hypertension related to end-stage chronic obstructive pulmonary disease. J Heart Lung Transplant 2012;31:373-80.

26. Belle-van Meerkerk G, Cramer MJ, Kwakkel-van Erp JM, et al. Pulmonary hypertension is a mild comorbidity in end-stage cystic fibrosis patients. J Heart Lung Transplant 2013;32:609-14.

27. Armstrong HF, Schulze PC, Bacchetta M, et al. Impact of pulmonary hypertension on exercise performance in patients with interstitial lung disease undergoing evaluation for lung transplantation. Respirology 2014;19:675-82.

28. Kimura M, Taniguchi H, Kondoh Y, et al. Pulmonary hypertension as a prognostic indicator at the initial evaluation in idiopathic pulmonary fibrosis. Respiration 2013;85:456-63.

29. Teramachi R, Taniguchi H, Kondoh Y, et al. Progression of mean pulmonary arterial pressure in idiopathic pulmonary fibrosis with mild to moderate restriction. Respirology 2017;22:986-90

30. Singh VK, Patricia George M, Gries CJ. Pulmonary hypertension is associated with increased post-lung transplant mortality risk in patients with chronic obstructive pulmonary disease. J Heart Lung Transplant 2015;34:424-9.

31. Gries CJ, Bhadriraju S, Edelman JD, et al. Obese patients with idiopathic pulmonary fibrosis have a higher 90-day mortality risk with bilateral lung transplantation. J Heart Lung Transplant 2015;34:241-6.

32. Chandrashekaran S, Keller CA, Kremers WK, et al. Weight loss prior to lung transplantation is associated

Cite this article as: Kim CY, Park JE, Leem AY, Song JH, Kim SY, Chung KS, Kim EY, Jung JY, Kang YA, Kim YS, Chang J, Lee JG, Paik HC, Park MS. Prognostic value of pre-transplant mean pulmonary arterial pressure in lung transplant recipients: a single-institution experience. J Thorac Dis 2018;10(3):15781587. doi: $10.21037 /$ jtd.2018.03.46 with improved survival. J Heart Lung Transplant 2015;34:651-7.

33. Glanville AR, Estenne M. Indications, patient selection and timing of referral for lung transplantation. Eur Respir J 2003;22:845-52.

34. Paik HC, Haam SJ, Lee DY, et al. The fate of patients on the waiting list for lung transplantation in Korea. Transplant Proc 2012;44:865-9.

35. Orens JB, Estenne M, Arcasoy S, et al. International guidelines for the selection of lung transplant candidates: 2006 update--a consensus report from the Pulmonary Scientific Council of the International Society for Heart and Lung Transplantation. J Heart Lung Transplant 2006;25:745-55.

36. Paik HC, Haam SJ, Lee DY, et al. Donor evaluation for lung transplantation in Korea. Transplant Proc 2012;44:870-4.

37. Kasimir MT, Seebacher G, Jaksch P, et al. Reverse cardiac remodelling in patients with primary pulmonary hypertension after isolated lung transplantation. Eur J Cardiothorac Surg 2004;26:776-81.

38. Magruder JT, Shah AS, Crawford TC, et al. Simulated Regionalization of Heart and Lung Transplantation in the United States. Am J Transplant 2017;17:485-95.

39. Tonelli AR, Fernandez-Bussy S, Lodhi S, et al. Prevalence of pulmonary hypertension in end-stage cystic fibrosis and correlation with survival. J Heart Lung Transplant 2010;29:865-72.

40. Scarsini R, Prioli MA, Milano EG, et al. Hemodynamic predictors of long term survival in end stage cystic fibrosis. Int J Cardiol 2016;202:221-5. 